\title{
Productivity Growth and Sectoral Interactions under Domar Aggregation: A Study for the Brazilian Economy from 2000 to 2014
}

\section{Theo Santini}

Instituto de Pesquisa Economica Aplicada

Ricardo Araujo ( $\nabla$ rsaaraujo@unb.br)

University of Brasilia https://orcid.org/0000-0001-5126-4418

\section{Research}

Keywords: Domar aggregation, Brazilian economy, sectoral interactions

Posted Date: July 29th, 2020

DOI: https://doi.org/10.21203/rs.3.rs-47867/v1

License: (c) (i) This work is licensed under a Creative Commons Attribution 4.0 International License.

Read Full License

Version of Record: A version of this preprint was published at Journal of Economic Structures on August 2nd, 2021. See the published version at https://doi.org/10.1186/s40008-021-00243-7. 


\title{
Productivity Growth and Sectoral Interactions under Domar Aggregation: A Study for the Brazilian Economy from 2000 to 2014
}

Theo Santini Antunes

\author{
Brazilian Institute of Applied Economics, Ipea, Brazil \\ and \\ Ricardo Azevedo Araujo* \\ Department of Economics, University of Brasilia, Brazil
}

\begin{abstract}
In this paper, we use the Domar aggregation approach to study the evolution of productivity growth in Brazil from 2000 to 2014, thus allowing us a disaggregated assessment of the issue. We found that the overall performance of the Brazilian economy can be explained not only by the poor performance of its sectors but also in terms of diminishing industrial density, with fewer backward and forward connections amongst industries in terms of chains of intermediate inputs. Besides, despite the relatively high density of the manufacturing sector, it performed a negative role concerning aggregate productivity growth both directly and indirectly. Directly insofar as that sector had negatives productivity growths during the period under consideration, and indirectly due to its high interconnection, which spread negative rather than positive productivity gains across the economy. Therefore, to improve the poor performance of the Brazilian economy, it is mandatory to restore the capability of the manufacturing sector of yielding and spreading productivity gains.
\end{abstract}

* Corresponding author. 


\section{Introduction}

At least since Adam Smith, economists acknowledge productivity growth as the primary source of the wealth of nations. Solow's (1956) growth model highlights that the growth rate of per capita output, capital and consumption is given by the exogenous growth rate of technological change. But within that framework, productivity or the total factor productivity (TFP) is calculated as a residual, which is somewhat unsettling. Since then, several authors have worked on what became known as growth accounting [see, e.g. Hulten (2009) and Jorgeson et al. (1987)]. Notwithstanding the considerable literature that followed the Solow's (1957) first attempt to measure TFP, most of the estimates underestimate the contribution of intermediate inputs when tackling productivity growth insofar as they do not consider them explicitly. In the present work, we fill this gap paying particular attention to the role of intermediate inputs in analysing productivity growth ${ }^{1}$ of the Brazilian economy from 2000 to 2014.

After an initial and consistent period of productivity growth during the second half of the last century, the productivity of the Brazilian economy remained stagnant since the eighties [see e. g. Nassif et al. (2020)]. Barbosa-Filho \& Pessôa (2014) and de Souza \& da Cunha (2018) registered a resurge of productivity growth at the beginning of the last decade. Still, it lasted until the 2008 crisis, with both mostly sectoral and aggregate productivity growth declining after that ${ }^{2}$. Some factors help us to disentangle this path. A crucial one is related to the intense deindustrialisation process registered in the last decades. The wane of manufacturing share in the national income share is not just the outcome of a faster decline in the price of manufacturing goods when compared to the cost of services. Even if one calculates the shares of different sectors in terms of constant prices, as opposed to current prices, will conclude that manufacturing value-added is decreasing. Besides, the deindustrialisation in Brazil is premature, happening at lower

\footnotetext{
${ }^{1}$ What generally differs among distinct methodologies is the definition of output and inputs. Concerning outputs, it is usually used some description of value-added or gross production. Among inputs, normally, some set involving labour, types of capital and, sometimes, intermediate goods are applied. Concerning different theoretical ways to measure productivity growth see e.g. Baumol \& Wolff (1989), Ten Raa \& Shestalova (2011), Wolff (2013). See also Fox (2012) about dis(aggregating) productivity growth and De Juan \& Eladio (2000) for a survey on productivity growth within a input-output framework.

${ }^{2}$ Aggregate productivity growth grew almost 15\% between 2000 and 2009, and then it has decreased until 2014, nearly offsetting the previous increase.
} 
levels of per capita income than the average of industrialised countries. And the migration of the labour force is occurring towards final services, which have lower productivity than the business services. The outcome is a reduction in overall productivity gains.

Another factor that can explain the difficulties faced by the Brazilian industry is a decrease in the density of the economy, as defined by the existing interconnection amongst sectors. A higher density ${ }^{3}$ means the existence of more forwarding and backward linkages amongst the industries, which is essential to spread productivity gains trough vertically integrated sectors. One could argue that such a decrease is the outcome of integration to the system of global value creation. As the global economy is structured around global value chains (GVCs), [see, e.g. Gereffi and Fernandez-Stark (2011)] the extent of participation in those chains seems to be an important explanatory variable to the decrease ${ }^{4}$ in domestic density. But Brazil, like other Latin America's economies, remains poorly integrated in terms of GVCs [see, e.g., and Andreoni and Tregena (2020)], which does not explain the density reduction.

To fully understand the importance of density to productivity growth is essential to bear in mind that industries do not only benefit from a productivity increase in its own production, but also from increased productivity in other sectors from which it acquires inputs, and this also generates impacts for aggregate productivity. Intermediate inputs are produced goods that link industrial sectors and have a unique role in spreading productivity growth amongst sectors [see, e.g. Aulin-Ahmavaara (1999)]. According to Jones (2011), intermediate goods ${ }^{5}$ provide links between industries that create a

\footnotetext{
${ }^{3}$ The complex literature advanced by Hausmann et al. (2007) highlights an increase of density as a possible source of better growth performance. In the presence of an intermediate service sector, the shift of resources to the service sector may enhance rather than decrease aggregate productivity growth even if the productivity growth of the service sector is lower than that of the industrial sector.

${ }^{4}$ Andreoni and Tregena (2020, p. 327) highlightes this trade-off by reporting that "(...) in a number of cases, middle-income countries that have attempted to integrate globally have also ended up 'de-linking domestically' and hollowing out the domestic manufacturing sector".

5 As pointed out by Amit and Konings (2007), and Goldberg et al. (2010), such goods allow for quality improvement in final products and broader participation of a country in international trade. Besides, its increased availability may facilitate product diversification and trigger pro-competition effects, inducing cost reductions and improved diversification, with the creation of productive linkages and spillover effects. The notion that linkages across industries can be crucial to economic performance dates back at least to
} 
multiplier. He argues that high productivity in an industry requires a high level of performance along many dimensions. The author proposes that linkages are a crucial part of the explanation by delivering a noteworthy example:

“(...) intermediate goods provide links between sectors that create a multiplier. Low productivity in electric power generation - for example, because of theft, inferior technology, or misallocation - makes electricity more costly, which reduces output in banking and construction. But this in turn makes it harder to finance and build new dams and therefore further hinders electric power generation." Jones (2011, p. 1-2)

Then to provide a more in-depth analysis of the behaviour of both sectoral and aggregate Brazilian productivity and economic growth between 2000 and 2014, we use here the Domar aggregation approach. For the best of our knowledge, this is the first time this method is adopted for studying the Brazilian economy. The advantage of this method is that it can capture not only the productivity growth contributions of individual sectors ${ }^{6}$ but those gains that accrue from the intermediate goods. A characteristic of Domar aggregation is that it is not a weighted average, but a weighted sum of sectoral productivity growths. Moreover, the sum of its weights is higher than unity in economies with intermediate inputs. The added Domar weights then represent the potential for interconnection and linkages between sectors, capable of propagating productivity growth throughout the economy.

After Domar (1961), several authors improved the method theoretically ${ }^{7}$ and used it empirically ${ }^{8}$ to perform growth accounting. Some essential theoretical works are Hulten (1978) which related the Domar aggregation with a macro production possibility frontier. Jorgeson et al. (1987) is a seminal work about the usage of Domar aggregation method

Leontief (1936), which introduced the field of input-output economics. Hirschman (1958) emphasised the role of forwarding and backward linkages to economic development.

${ }^{6}$ We split industrial sectors into a 48, 10 and 3 levels of aggregation to structurally analyze the Brazilian economy and to deliver a sectoral and aggregate productivity growth evaluation and its interactions over the given period.

${ }^{7}$ See also Hulten (2009) for a complete survey on growth accounting and its relationship with Domar aggregation and other methods.

${ }^{8}$ Some interesting empirical works are e.g. Oulton \& O'Mahony (1994) about productivity growth in United Kingdon manufacturing industries, Jorgenson \& Stiroh (2000) and Oliner \& Sichel (2000) concerning United States, Timmer \& van Ark (2005) about Europe Union and focusing on Information and Communication Technology sectors, Gu \& Yan (2016) about China and Cao, et. al. (2019) regarding several developed countries. 
with several theoretical improvements, while Aulin-Ahmavaara (1999) formulated explicitly the output price reductions caused by the productivity in downstream sectors. More recently, Ten Raa \& Shestalova (2011) and Balk (2019) also have delivered essential contributions 9 .

Given the usefulness of Domar aggregation, particular fields of research have used it as a tool to calculate and decompose productivity growth. It has been useful for instance to study the implications of the Baumol Cost Disease within input-output frameworks [e.g. Oulton (2001), Sasaki (2007), Baumol (2011), Hartwig and Krämer (2019) and Sasaki (2020)]. It has also been adopted to study production networks and shock propagation channels as a mechanism for transforming microeconomic shocks into macroeconomic fluctuations [e.g. Acemoglu et al. (2012), Carvalho (2014), Carvalho \& Salehi (2019) and Baqaee \& Farhi (2019)]. Although there are several works about sectoral and aggregate productivity growth for the Brazilian economy, using numerous TFP methods ${ }^{10}$, for the best of our knowledge, this is the first paper that adopts the Domar aggregation approach.

With this approach, we confirm some result and find new ones. Besides, after decomposing the total productivity growth for three macro sectors, we confirmed the results found by de Souza \& da Cunha (2018). Services and primary industries macro sectors had a positive impact on average for productivity growth, albeit macro manufacturing sector contributed with negative productivity growth on average. But our study allows us to consider another dimension that was not studied by those authors, which is the multiplicative effect of propagating productivity growth due to Domar weights ${ }^{11}$. With this approach, we conclude that manufacturing had a high sectoral density compared with its value-added share, albeit it seems to have spread negative productivity growth in most of the given period. These findings reassert the importance of the

\footnotetext{
${ }^{9}$ Ten Raa \& Shestalova (2011) buids the Domar aggregation by theoretically relating it with other types of productivity decompositions in the literature creating a common framework. Balk (2019) buids the Domar aggregation dispensing with some usual assumptions, making them more flexible.

${ }^{10}$ See de Souza \& da Cunha (2018) for a work using similar period of time as here and for a review of articles about Brazil using TFP methodology.

${ }^{11}$ Services, manufacturing and primary industries macro sectors presented, respectively $51 \%, 44 \%$ and $5 \%$ of total sectoral density. Though, considering their values added share in GDP, on average their contributions were $68 \%, 27 \%$ and $5 \%$, respectively.
} 
industrial sector as one of the main drivers of growth. Had this sector presented a better performance during the time under consideration, the overall productivity growth of the Brazilian economy would be better both by the direct and indirect channels.

We organise this paper as follows: besides this brief introduction, in the next section, there is a theoretical review of Domar aggregation and its usage. Then, in the third section, we use the methodology as the analytical basis for the empirical analysis. The fourth section delivers the data analysis for the Brazilian economy using WIOD data and both sectorial and aggregated productivity calculations, segmented in a 48, 10 and 3 sector levels of aggregation. Finally, section 5 concludes the paper.

\section{Methodology}

\subsection{Database}

We analyse the Brazilian economy between 2000 and 2014 by using the Domar aggregation approach. To do that, we use the Socio-Economic Accounts (SEA) data from the World Input-Output Database (WIOD). The SEA tables provide us with all the necessary data ${ }^{12}$ and are organised in a directly compatible ${ }^{13}$ way, as shown by Dietzenbacher et al. (2013) and Timmer et al. (2015). The data comprises the period between 2000 and 2014, and 48 sectors for the Brazilian economy. Aiming to improve the visualisation results, we have split the sectors, besides the original 48 levels of aggregation from the data ${ }^{14}$, to 10 and 3 levels of aggregation as can be seen in detail in the appendix.

\subsection{Method}

\footnotetext{
${ }^{12}$ We use, from SEA tables, sectorial capital stocks, labor expenditures, hours worked, gross output and value added at current and constant prices. The only necessary data that is not explicitly in SEA tables is sectoral capital stock growth rate in constant prices. We have used an appropriated deflator to calculate it from nominal capital stock.

${ }^{13}$ The (SEA) WIOD data is built in a way that the value added per sector is equal to the sum of expenses of labor and capital inputs in one hand and equal to the difference between sectorial gross output and intermediate input in other hand, just like in the model provided.

${ }^{14}$ The original subdivision of sectors is given by the ISIC (International Standard Industrial Classification of All Economic Activities) revision n. 4, from the United Nations Statistics Division, which can be found at https://unstats.un.org/unsd/classifications/Econ/ISIC\#isic1 .
} 
Following the methodology proposed by Jorgeson et al. (1987) and Jorgenson and Stiroh (2000), consider an economy with $n$ discinct sectors in which each of them can sell its products both to final demand and intermediate demand from other industries. The expression below shows that the nominal gross output production of the $i$ th $\operatorname{sector}\left(P_{i} Q_{i}\right)$ is sold both to final demand $\left(P_{i} Y_{i}\right)$ and to intermediate demand $\left(\sum_{j=1}^{n} P_{i} Q_{i j}\right)$ from all $j$ sectors that require the good or service produced by $i$ as an intermediate input to its production:

$$
P_{i} Q_{i}=P_{i} Y_{i}+\sum_{j=1}^{n} P_{i} Q_{i j}
$$

where $P_{i}$ represents the selling price of sector $i$ goods, both to final and intermediate demand. Moreover, $Q_{i}, Y_{i}$ and $Q_{i j}$ are, respectively, real gross output, real final demand and real intermediate demand produced by the $i$ th sector. Symmetrically, consider that the nominal gross output of all $i$ sectors can also be described from its inputs side. It means that each sector $i$ yields a homogeneous good or service that requires, for its production, an intermediate input set bought from other sectors $\sum_{j=1}^{n} P_{j} Q_{j i}$, as well as a set of capital and labour inputs, respectively defined as $P_{K i} K_{i}$ and $P_{L i} L_{i}$, as shown by the equation below, where all the $P$ terms represent prices and the accompanying terms real quantities:

$$
P_{i} Q_{i}=P_{L i} L_{i}+P_{K i} K_{i}+\sum_{j=1}^{n} P_{j} Q_{j i}
$$

The sectoral nominal value-added $\left(P_{i}^{V} V_{i}\right)$, or net output, is, therefore, the difference between their respective gross production and intermediate demand. In our model, it is precisely equal to the sum of sectoral primary inputs expenditures, as shown by next expression:

$$
P_{i}^{V} V_{i}=P_{i} Q_{i}-\sum_{j=1}^{n} P_{j} Q_{j i}=P_{L i} L_{i}+P_{K i} K_{i}
$$

Equalising (1) to (1'), and summing up for all the $i$ sectors, we find the definition of the economy gross domestic product (GDP). It can be measured both from the sum of all final demands and value-added. It is worth noting that in that process the intermediate inputs demand and supply cancel out each other avoiding double counting.

$$
\sum_{i=1}^{n} P_{i} Y_{i}=\sum_{i=1}^{n} P_{i}^{V} V_{i}=G D P
$$


Assume that sectoral production technology is described, in a more general form, as a sectoral production function that relates time and its inputs - both primary and intermediate - with the gross sectoral product. The Hicks-neutral type of this function is:

$$
Q_{i}=Q_{i}\left(L_{i}, K_{i}, X_{j i}, t\right)
$$

Differentiating totally (3) with respect to time, using (1') and considering that a hat $\left(^{\wedge}\right)$ denotes growth rate, we find the next equation that describes the $i$-th sector multifactor productivity growth. For the sake of notation simplicity, the sectoral inputs to gross output shares are denoted ${ }^{15}$ by $v_{L i}=\frac{P_{L i} L_{i}}{P_{i} Q_{i}}, v_{k i}=\frac{P_{K i} K_{i}}{P_{i} Q_{i}}$ and $v_{Q j i}=\sum_{j=1}^{n} \frac{P_{j} Q_{j i}}{P_{i} Q_{i}}$.

$$
\hat{q}_{i}=\hat{Q}_{i}-v_{L i} \hat{L}_{i}-v_{k i} \widehat{K}_{i}-v_{Q j i} \hat{Q}_{j i}
$$

The term $\hat{q}_{i}$ denotes sectoral multifactor productivity growth. The multifactor productivity growth - MFP growth hereafter - is defined as the residual of the difference between the growth rate of the gross product and the growth rate of the inputs, weighted by the share of the input's value in the value of the gross product [see, e.g. Cas \& Rymes (1991)]. One of the first authors to formalise the concept of $\mathrm{MPF}^{16}$ growth was Hulten (1978). Note that the equation above can be written in discrete time using a Törnquist ${ }^{17}$ or translog discrete-time approximation, where the $\Delta$ term is the difference between the variable in the current and previous time:

$$
\Delta \ln q_{i t}=\Delta \ln Q_{i t}-\frac{\left(v_{L i t}+v_{L i t-1}\right)}{2} \Delta \ln L_{i t}-\frac{\left(v_{k i t}+v_{k i t-1}\right)}{2} \Delta \ln K_{i t}-\frac{\left(v_{Q j i t}+v_{Q j i t-}\right)}{2} \Delta \ln Q_{j i}
$$

\footnotetext{
${ }^{15}$ Using (1') it's easy to see that $\mathrm{v}_{\mathrm{Li}}+\mathrm{v}_{\mathrm{ki}}+\mathrm{v}_{\mathrm{Qji}}=1$.

${ }^{16}$ According to Oulton \& O’Mahony (1994), the MPF growth is, theoretically speaking, the rate at which output would have increased in some period if all inputs had remained constant. Furthermore, it is noteworthy that if we calculate MPF growth over some period and it turns out to be about zero, then we can at least say that any eventual growth in labor productivity must have been due to increased use of other inputs.

17 See, for example, Diewert (1976), Ten Raa \& Shestalov (2011) and Hulten (2009) about the use of Törnquist index for discrete time aproximations and uses in productivty growth theory. The nickname Translog index is due to Diewert (1976), who has shown that the approximation is exact for the translog production function.
} 
We can describe the sectoral gross output growth rate as the average mean of the growth rates of both real net output and intermediate inputs, weighted by its respective shares of the gross production. In the equation below, the term $v_{V i}$ equals to $v_{L i}+v_{k i}$.

$$
\hat{Q}_{i}=v_{V i} \widehat{V}_{i}+v_{Q j i} \hat{Q}_{j i}
$$

Using (4) and (5) and after some algebraic manipulations, it is possible to find the following expression, that relates the growth rate of the sectoral value-added with the growth rate of capital stock, labour force and productivity:

$$
v_{V i} \widehat{V}_{i}=v_{k i} \widehat{K}_{i}+v_{L i} \widehat{L}_{i}+\hat{q}_{i}
$$

From an aggregate point of view, the GDP of the economy is described as the sum of all sectoral values added (or amount of all sector final demand). That is, being the nominal GDP of the whole economy $P Y$, we have that $P Y=P_{v} V=\sum_{i=1}^{n} P_{i}^{V} V_{i}$. We use a general function that relates the aggregated value added with the relevant inputs and time $^{18}$ :

$$
V=f(L, K, t)
$$

When differentiating totally (7) with respect to time, and after some algebraic manipulations, we find an expression that connects the growth rate of aggregate productivity, defined as $\hat{q}$, with the growth rate of the total value added of the economy and the weighted sum of the sectorial primary inputs capital and labour:

$$
\hat{q}=\widehat{V}-\sum_{i=1}^{n} \frac{P_{L i} L_{i}}{\sum_{i=1}^{n} P_{i}^{V} V_{i}} \widehat{L}_{i}-\sum_{i=1}^{n} \frac{P_{K i} K_{i}}{\sum_{i=1}^{n} P_{i}^{V} V_{i}} \widehat{K}_{i}
$$

Aiming to unearth an equation that relates the productivity growth rate of the whole economy with the growth rates of sectoral productivity - the Domar aggregation we combine (6) and (8) to obtain:

$$
\hat{q}=\sum_{i=1}^{n} \frac{P_{i} Q_{i}}{\sum_{i=1}^{n} P_{i}^{V} V_{i}} \hat{q}_{i}
$$

Expression (9) is known as the Domar aggregation of sectoral MPF growth. Although Domar (1961) was the first to find this relationship formally, other authors such

\footnotetext{
${ }^{18}$ This can be explicitly found using equations (1) and (1'), as in (1'').
} 
as Hulten (1978) and Jorgeson et al. (1987) later improved it. In discrete-time, we can write the expression (9) as:

$$
\Delta \ln q=\sum_{i=1}^{n} \frac{1}{2}\left(\frac{P_{i t} Q_{i t}}{\sum_{i=1}^{n} P_{i t}^{V} V_{i t}}+\frac{P_{i t-1} Q_{i t-}}{\sum_{i=1}^{n} P_{i t-1}^{V} V_{i t-1}}\right) \Delta \ln q_{i t}
$$

Note that the weighted sum of sectoral MFP has the striking feature that it sums to more than unity ${ }^{19}$ in economies with intermediate goods. The higher the participation of intermediate inputs in the economy, the higher the sum of the weightings. Regarding the 'sum to more than the unity' of Domar aggregation and its intuition, Jorgenson (2018, p. 881) considers that:

"A distinctive feature of Domar weights is that they sum to more than one, reflecting the fact that an increase in the growth of the industry's productivity has two effects: the first is a direct effect on the industry's output and the second an indirect effect via the output delivered to other industries as intermediate inputs."

Similarly, Oulton \& O’Mahony (1994, p. 14) explains the intuition behind the role of intermediate inputs in the aggregated productivity growth and the Domar weights behaviour:

"The intuitive justification for the sum of the weights exceeding one is that an industry contributes not only directly to aggregate productivity growth but also indirectly, through helping lower costs elsewhere in the economy when other industries buy its product".

Domar aggregation method establishes a link between the sectoral level productivity growth and aggregate productivity growth. Productivity benefits of the aggregate economy may exceed the average productivity gains across sectors given that flows of intermediate inputs among sectors contribute to total productivity growth by allowing productivity gains - or losses - in successive industries to augment one another. Moreover, the contribution of an industry to the overall productivity growth depends

\footnotetext{
${ }^{19}$ Accordingly to Ten Raa \& Shestalova (2011), more common productivity aggregation in the literature, like aggregating sectoral TFP-growth (without explicitly dealing with intermediate inputs in sectoral production functions), can be represented as a simple weighted average of sectoral productivity growth. However, the aggregation of sectoral multifactor productivities growth comprises a tricky aggregation issue, when dealing with input-output economies, which has been analyzed by Domar (1961). The point is that the national product of an economy does not comprise the sum of all gross output, but only the sum of net outputs. Avoiding for double counting, the Domar aggregation spawns an aggregation where the weights sum to more than one.
} 
(besides the direct productivity growth in this sector) on the efficiency changes in the production of its intermediate inputs. To clarify the mechanism in which the direct and indirect effects above mentioned behave within the model, we substitute equations (1') and (2) into the numerator of (9) to obtain:

$$
\hat{q}=\sum_{i=1}^{n} \frac{P_{V i} V_{i}}{\sum_{i=1}^{n} P_{i}^{V} V_{i}} \hat{q}_{i}+\sum_{i=1}^{n} \frac{\sum_{j=1}^{n} P_{j} Q_{j i}}{\sum_{i=1}^{n} P_{i}^{V} V_{i}} \hat{q}_{i}
$$

Disaggregating the second term of the expression above for all sectors, we get:

$$
\hat{q}=\sum_{i=1}^{n} \frac{P_{V i} V_{i}}{\sum_{i=1}^{n} P_{i}^{V} V_{i}} \hat{q}_{i}+\frac{\sum_{j=1}^{n} P_{j} Q_{j 1}}{\sum_{i=1}^{n} P_{i}^{V} V_{i}} \hat{q}_{1}+\frac{\sum_{j=1}^{n} P_{j} Q_{j 2}}{\sum_{i=1}^{n} P_{i}^{V} V_{i}} \hat{q}_{2}+\ldots+\frac{\sum_{j=1}^{n} P_{j} Q_{j n}}{\sum_{i=1}^{n} P_{i}^{V} V_{i}} \hat{q}_{n}
$$

Note that the sum of the value-added weights, in the first term of the equation above right-hand side, is precisely one. The terms on the right, however, depict the sectoral productivity impacts from intermediate inputs deliveries. Therefore, the weights on the right are the ones that exceed the unity considering the overall aggregation. From the equation above it must be clear that the higher the degree of interconnection, or density of the economy in terms of intermediate inputs deliveries, the higher the potential of productivity growth augmenting given the growth of sectoral productivities.

To visualise the mechanism involved, assume that $\theta_{i j}=\frac{\sum_{j=1}^{n} P_{j} Q_{j i}}{\sum_{i=1}^{n} P_{i}^{V} V_{i}}$ is the share of aggregate demand for intermediate inputs in the economy, which measures the degree of sectoral density or sectorial interconnection. Substituting $\theta_{i j}$ into equation (10) we find the equation below:

$$
\hat{q}=\sum_{i=1}^{n} \frac{P_{V i} V_{i}}{\sum_{i=1}^{n} P_{i}^{V} V_{i}} \hat{q}_{i}+\sum_{i=1}^{n} \theta_{i j} \hat{q}_{i}
$$

The term $\sum_{i=1}^{n} \theta_{i j}$ measures the degree of interconnection, or density, of the economy, since it defines the relative importance of vertical interaction of the sectors. The greater the term $\theta_{i j}$ is in each $i$ th sector, the more significant is the sectoral capability to spread productivity and to augment the sum of the whole economy due to Domar weights. Let us suppose that, for some reason, the density $\theta_{i j}$ of some sector $i$ increases, due to a more significant share of intermediate demand by the given sector in the economy's GDP. Then, by differentiating the aggregate productivity growth with respect to $\theta_{i j}$ in (12) we have that: 


$$
\frac{\partial \hat{q}}{\partial \theta_{i j}}=\hat{q}_{i}>0
$$

Hence, if the sectoral productivity growth in the given sector is positive, then an increase $^{20}$ in $\theta_{i j}$ leads, by itself, to a higher aggregate productivity growth, given all sectoral productivity growth. In this vein, if the share of intermediate goods in the economy increases, the sum of Domar weights increases as well. In that case, the economy is subject to a higher density ${ }^{21}$ that generates an augmented potential of aggregate productivity growth. Finally using equations (4) and (5) and summing up for all sectors, it is possible to find an expression concerning the interactions between aggregate productivity growth and economic (GDP) growth:

$$
\hat{v}=\sum_{i=1}^{n} \frac{p_{i} v_{i}}{\sum_{i=1}^{n} P_{i}^{V} V_{i}} \hat{v}_{i}=\sum_{i=1}^{n} \frac{p_{i} Q_{i}}{\sum_{i=1}^{n} P_{i}^{V} V_{i}} \hat{q}_{i}+\frac{p_{l i} L_{i}}{\sum_{i=1}^{n} P_{i}^{V} V_{i}} \widehat{L}_{i}+\frac{p_{k i} K_{i}}{\sum_{i=1}^{n} P_{i}^{V} V_{i}} \widehat{K}_{i}
$$

Thus, the aggregate value-added growth rate can be viewed as a weighted sum of labour, capital and Domar productivity growth contributions. In the next section, we use expressions (4') and (9') to calculate, respectively, the sectorial and aggregate productivity growth.

\section{Results and Discussion}

In this section, we use expressions (4') and (9') as a basis for calculating the sectorial and aggregate productivity growth. Figure 1 shows, on the top side, that the manufacturing sectors were the ones that used the most intermediate inputs in its gross output.

\footnotetext{
${ }^{20}$ Indeed, there are more than one possibly way that can lead to an augmented sum of Domar weights, or density of the economy. It can happen both if one or more sectors start to be more integrated, demanding higher shares of intermediate inputs for its production, or if one or more sectors with a structurally high share of intermediate inputs in its gross output increases its share in the whole economy in a way that led to a higher sum of Domar weights.

${ }^{21} \mathrm{An}$ increase of density as a source of better growth performance is highlighted by the complex literature advanced by Hausmann and Klinger (2006). According to this view, industries with higher 'implied productivity' are those whose are well connected with other industries of the economy, being this connection made by the supply of intermediate inputs. Hidalgo \& Hausmann (2009) went a step further and concluded that the ease in which a country moves from the production of one good to another depends on its position in the 'product space', which is the network connections between various sectors.
} 


\section{[Figure 1 goes here]}

Albeit service sectors were very heterogeneous compared with primary industries, it still had, on average, a more substantial share of intermediate inputs than primary sectors. Concerning value-added share in GDP, when summing up all service sectors, they represented the majority share in GDP compared with the other two macro sectors. However, the manufacturing sectors were the ones with higher average intermediates inputs in GDP - or density as defined in the last section - compared to services and primary industries macro sectors. Whereas the services sectors have had extensive heterogeneity regarding intermediate inputs to gross output shares, it did not happen concerning sectoral density. Finally, both the manufacturing and services sectors presented relevant shares of Domar Weights, more relevant potential to spread productivity growth than primary industries sectors.

Figures 2 and 3 below show a time series analysis for the ten sectors level of aggregation about both sectorial GDP share and intermediate inputs to gross output share. Note that, in figure 2, while agriculture, forestry and fishing sectors have shown some stability in the GDP share, manufacturing industries have had a slight decline during the given period. Most services sectors have shown an increase in its share, with the exceptions of the information and communication sector and other traditional services sector.

\section{[Figure 2 goes here]}

Concerning sectoral behaviour about intermediate input to gross output share, displayed by Figure 3, note that manufacturing industries have been the sector with the highest demand for intermediate inputs compared to its gross output with something around sixty to eighty per cent during the given period. Agriculture, forestry and fishing experienced a slight increase to something above forty per cent of intermediate inputs share. Mining, quarrying, electricity, gas and water supply has had a significant share as well, above most services sectors. Note that the services sectors, as expected from previous analysis, have exhibited a heterogeneous pattern, with a relatively high share in sectors such as financial and insurance activities and meagre share in real estate activities.

\section{[Figure 3 goes here]}


We provided in table 1 below calculations for sectoral density (intermediate input to GDP share), value-added share in GDP, sectoral Domar weights and sectoral (MFP) productivity growth for both 10 and 3 sector levels of aggregation. Analysing the time series, we found another pattern of change in most variables studied before and after 2008 confirming the findings of de Souza \& da Cunha (2018) who identified the same pattern by using an alternative methodology. So we decided to split the analysis for two distinct periods: from 2000 to 2008 and from 2009 to 2014 . Considering the average of the entire period analysed - 2000 to 2014 - the sum of Domar weights is 2,042 . That means that in addition to the sum of the shares of the values added to GDP, which add up to the unit, there is an extra weight of 1.042 relative to the sectorial densities. This additional portion of the sums of the sectorial weights refers to the degree of sectorial interconnection. It is clear from table 1 that the macro sector with the highest Domar weight is the services one, with $52 \%$, followed by the manufacturing and primary sector macro sectors, with $43.5 \%$ and $4.5 \%$, respectively.

\section{[Table 1 goes here]}

Although the manufacturing sector is the one with the most significant capacity to propagate productivity growth in the economy, due to its high sectoral density, it seems to have bred decrease in productivity, due to its average $-0.5 \%$ annual MFP growth. That has a double impact - direct and indirect - in decreasing the aggregate productivity of the economy, especially after 2008. The primary sector was the one that generated the highest average annual productivity growth, with an average of $1.8 \%$ per year. However, the sector showed low interconnection potential and, therefore, low capacity to propagate productivity growth. The services sector, on the other hand, although it had a vital ability to spread productivity growth, presented a modest average of MFP growth, with an annual average of $0.5 \%$. However, it showed a heterogeneous behaviour when the sector is observed in more disaggregated terms.

Regarding sectoral Domar weights, considering the whole period yearly average, the service sector had a 1.05 Domar weight, followed by 0.89 in manufacturing and only 0.093 in the primary industries. It is worth noting that although the services sector was the macro sector with higher Domar weight, with about $52 \%$, it had almost $68 \%$ of the total value-added. The manufacturing sector presented $43.5 \%$ of the average Brazilian Domar weight but something around $27 \%$ of total value-added. This fact shows that the 
impact of intermediate inputs in the manufacturing sector generates a boost in its Domar weight compared to its value-added share ${ }^{22}$. The primary industries sector, in its turn, had only $4.5 \%$ of total average Domar weight, with almost $5 \%$ of the value-added share, on average.

However, despite both macro sectors - manufacturing and services - have had the high capacity on potentialising productivity growth throughout the economy, due to its Domar weights, many manufacturing industries showed negative productivity growth during the period. Thus the high density of the manufacturing macro sector acted in a negative way concerning the aggregate productivity growth, helping to spread and increase negatives productivity growths. The services macro sector showed a positive average productivity growth, and then its relatively high Domar weight has performed a positive effect on potentialising productivity growth. The primary industries macro sector, albeit it was the sector with higher average productivity growth, it had the lowest sectoral Domar weight, with a relatively limited capacity of boost aggregate productivity growth.

\section{[Figure 4 goes here]}

Figure 3 above shows the aggregate Brazilian Domar weight behaviour between 2000 and 2014. It presented a slightly upward trend until 2008, of almost 5\%. After 2008, the pattern has reverted and has more than compensated previous growth. This fact indeed spawned a decrease of average Brazilian sectoral density and, therefore, a decline in both sum of Domar weights and structural capacity in potentialising sectoral productivity growth at the aggregate level. That fact is easier to see in figures 5 and 6 below, which show the aggregate productivity growth measured by the Domar aggregation method for the whole economy and decomposed by macro sectors, respectively. Both figures show the yearly and cumulative Domar aggregate productivity growth.

\footnotetext{
${ }^{22}$ These findings corrobarates the view emphasized by authors such as Szirmai (2012) and Tregenna (2009), among others, that the manufacturing plays an important role in the growth process due to its forwarding and backward linkages, which are more pronounced than in the service and agricultural sectors. More recently, Gabriel et. al. (2020), using panel data and input-output matrix show that the manufacturing industry's output multipliers and employment are higher than that from the other sectors for developing countries, thus confirming also confirmed the view that productive linkages and spillover effects are stronger within manufacturing industries [Szirmai et al. (2013)].
} 


\section{[Figure 5 goes here]}

Using equation (9'), it was possible to calculate the yearly and aggregate cumulative productivity growth using the Domar aggregation method. Indeed, given sectoral productivities growths and sectoral densities, the Brazilian aggregate productivity growth increased, from a cumulative point of view, from 2000 to 2010 . However, despite that behaviour, the aggregate productivity growth was negative in 2001, 2003 and 2009. However, after that and despite 2010, the yearly aggregate productivity growth was negative in all years, which led to an almost complete reversal of cumulative productivity growth previously undergone, from nearly 17\% cumulative growth in 2010 to roughly $3 \%$ in 2014.

\section{[Figure 6 goes here]}

We also show the behaviour of aggregate productivity growth in figure 6 . Still, this time it was decomposed by each of the three macro sectors weighted by its correspondent sectoral Domar weight. Although cumulative productivity growth in services and primary industries macro sectors were positive, that of the manufacturing sector was consistently negative due to its negative (MFP) productivity growths potentialised by its high Domar weight and sectoral density. It is interesting to note that although the Primary industries macro sector was the one with more consistent yearly MPF growth, its positive contribution to overall productivity was limited due to low density and Domar weight. The Services macro sector presented a relatively high variance in its annual productivity growth, but it still delivered most of the productivity growth in the economy thinking as an aggregate. After 2009, like aggregate productivity, the services macro sector showed a decrease in both cumulative and average yearly productivity growth.

As pointed out by Wolff (2014), there are two ways of increasing economic growth. The first one is by augmenting the factors available for production ('factor augmentation'), while the second one is by raising the rate of productivity growth. Table 2 below reveals the contribution of each input and decomposed Domar aggregate productivity growth for each unity of value-added for all the three macro sectors and the whole economy, considering the average of $2000-2014$ period.

[Table 2 goes here] 
Considering the three macro sectors and the economy as a whole, the average growth rate of value-added generated by the primary macro sector had a negative contribution from the labour input of $-18.5 \%$, a positive contribution of capital input of $44.9 \%$ and a vital productivity contribution of $73.6 \%$. The manufacturing sector obtained a positive contribution from primary inputs labour and capital with $61.4 \%$ and $103 \%$, respectively, but a considerable negative contribution of $-64.4 \%$ of productivity, for each added value generated. The services sector, in turn, had a positive contribution from either both labour and capital inputs and productivity growth, with $46.9 \%, 29.3 \%$ and $23.8 \%$, respectively. The average of each unit of the added value generated by the economy in the period, considering the economy as a whole, attained the contribution of $45.2 \%$ of labour input, $45.9 \%$ of capital and $8.9 \%$ of generated productivity measured by Domar aggregation. The result that the productivity growth in the service sector was higher than that of the industrial sector is somewhat surprising insofar as we would expect that the latter would have a higher productivity gain than the former ${ }^{23}$.

\section{Concluding Remarks}

In this paper, we use the Domar aggregation approach to study the evolution of productivity growth in Brazil from 2000 to 2014. This method was adopted to approach other countries, but for the best of our knowledge, this is the first time for the Brazilian economy. That is particularly important because it allowed us a disaggregated assessment of the Brazilian productivity and growth pattern during that period. We can explain the overall productivity performance of the Brazilian economy not only in terms of the poor performance of its sectors but also in terms of diminishing industrial density, with fewer backward and forward connections amongst industries in terms of chains of intermediate inputs $^{24}$.

\footnotetext{
${ }^{23}$ This hypothesis is commonly associate to the Baumol's model of unbalanced growth in which he assumes that the service sector is the stagnant one due to its lower productivy gains when compared to the industrial sector. Such view was confirmed empirically by a number of authors such as Appelbaum and Schettkat (1999) and Nordhaus (2008).

${ }^{24}$ The complexity literature advanced by Hausmann et al. (2007) highlights an increase of density as a possible source of better growth performance. In the presence of an intermediate service sector, the shift of
} 
Besides, despite the relatively high density of the macro manufacturing sector when compared to other sectors in the Brazilian economy, it performed a negative role concerning aggregate productivity growth both directly and indirectly. Directly insofar as that sector had negatives productivity growths during the period under consideration, and indirectly due to its high interconnection, which helped to spread negative rather than positive productivity growth across the economy. Therefore, to improve the poor performance of the Brazilian economy witnessed in recent years, it is mandatory to enhance the capability of Brazilian manufacturing macro sector to generate productivity growth. In sum, Brazil has failed in its task to deepen its industrial density. As a consequence, it has witnessed a prematurely shrink in the share of the manufacturing sector in GDP, being stuck in a middle-income trap.

\section{References}

Acemoglu, D., Carvalho, V. M., Ozdaglar, A. \& Tahbaz-Salehi, A. (2012). The Network Origins of Aggregate Fluctuations. Econometrica, 80(5), p. 1977-2016.

Amiti, M, and J. Konings (2007) Trade Liberalization, Intermediate Inputs, and Productivity: Evidence from Indonesia. American Economic Review 97(5): 1611-38.

Appelbaum, L and Schettkat, R. (1999). 'Are Prices Unimportant? The Changing Structure of the Industrialized Economies.' Journal of Post Keynesian Economics 21(3):387-398.

Andreoni, A. \& Tregenna, F. (2020). Escaping the middle-income technology trap: A comparative analysis of industrial policies in China, Brazil and South Africa. Structural Change and Economic Dynamics, 54, 324 - 340.

Araujo, R., de Paiva, M.. \& Santos, J. (2019). The role of intermediate inputs in a multisectoral balance-of-payments-constrained growth model: the case of Mexico. Economic Structures 8, 23.

Aulin-Ahmavaara, P. (1999). Effective Rates of Sectoral Productivity Change. Economic Systems Research, 349-363.

resources to the service sector may enhance rather than decrease aggregate productivity growth even if the productivity growth of the service sector is lower than that of the industrial sector. 
Balk M, B. (2019). A novel decomposition of aggregate total factor productivity change. Journal of Productivity Analysis, 1-11.

Baqaee, D. R. \& Farhi, E., 2019. The Macroeconomic Impact of Microeconomic Shocks: Beyond Hulten's Theorem. Econometrica, 87(4), p. 1155-1203.

Barbosa-Filho, F., \& Pessôa, S. (2014). Pessoal Ocupado e Jornada de Trabalho: uma releitura da evolução da produtividade. Revista Brasileira de Economia, 149-169.

Baumol, W. J. (1967). Macroeconomics of Unbalanced Growth: The Anatomy of Urban Crisis. The American Economic Review, 57(3), 415-426.

Baumol, W., \& Wolff, E. (1989). Three Fundamental Productivity Concepts: Principles and Measurement. Em F. G. R., Joan Robinson and Modern Economic Theory (pp. 638659). London: Macmillan.

Cao, J., S. Ho, M., Jorgenson, D., Ren, R., Sun, L., \& Yue, X. (2019). Industrial and aggregate measures of productivity growth in China, 1982-2000. Review of Income and Wealth, 485-513.

Carvalho, V. M., 2014. From micro to macro via production networks. Journal of Economic Perspectives, Volume 28, p. 23-48.

Carvalho, V. M. ,Tahbaz-Salehi, A. 2019. Production Networks: A Primer. Annual Review of Economics, Issue 11, p. 635-63.

De Juan, O., \& Eladio, F. (2000). Measuring Productivity from Vertically Integrated. Economic Systems Research, 65-82.

De Souza, T., \& da Cunha, M. (2018). Performance of Brazilian total factor productivity from 2004 to 2014: a sectoral and regional analysis. Economic Structures, 7, 24.

Dietzenbacher, Los, E., Stehrer, R., Timmer, M., \& de Vries, G. (2013). The Construction of World Input-Output Tables in the WIOD Project. Economic Systems Research, 71-98.

Diewert, E. W. (1976). Exact and Superlative Index Numbers. Journal of Econometrics, 115-145.

Domar, E. D. (1961). On The Measurement of Technological Change. Economic Journal, LXXI, 709-729. 
Ellery, R. (2014). Desafios para o Cálculo da Produtividade Total dos Fatores. Em C. R. De Negri F, Produtividade no Brasil: desempenho e determinantes, vol 1 (pp. 53-86). Brasília: IPEA:ABDI.

Fox, K. J. (2012). Problems with (dis)aggregating productivity, and another productivity paradox. Journal of Productivity Analysis, 37, 249-259.

Gabriel L. F., de Santana Ribeiro L. C., Jayme Jr F. G., da Costa Oreiro J.L. (2020) Manufacturing, economic growth, and real exchange rate: Empirical evidence in panel data and input-output multipliers. PSL Quarterly Review, 73 (292): 51-75.

Gereffi, G. and Fernandez-Stark, K. (2011). Global value chain analysis: a primer. Center on Globalization, Governance \& Competitiveness, Durham, NC.

Goldberg, P K, A Khandelwal, N Pavcnik and P. Topalova (2010) Imported intermediate Inputs and Domestic Product Growth: Evidence from India. The Quarterly Journal of Economics, 125(4), 1727- 1767.

Gu, W., \& Yan, B. (2016). Productivity Growth and International Competitiveness. Review of Income and Wealth, 1-21.

Hartwig, J., \& Krämer, H. (2019). The 'Growth Disease' at 50 - Baumol after Oulton. Structural Change and Economic Dynamics, 51, 463-471.

Hausmann, R., Hwang, J. and Rodrik, D. (2007). What you export matters. Journal of Economic Growth 12, 1-25.

Hausmann, R. and Klinger, B. (2007) The structure of the product space and the evolution of comparative advantage. CID working paper No. 146, April. Cambridge, MA: Harvard University, Center for International Development.

Hidalgo, C. and Hausmann, R. (2009). The building blocks of economic complexity. Proceedings of the National Academy of Sciences of the United States of America, 106(26), 10570-10575.

Hirschman, A. O. (1958. ). The Strategy of Economic Development. New Haven,: Yale University Press.

Hulten, C. R. (1978). Growth Accounting with Intermediate Inputs. Review of Economic Studies(45), 511-518. 
Hulten, C. R. (2009). Growth Accounting. NBER Working Papers 15341.

Jones, C. I. (2011). Intermediate Goods and Weak Links in the Theory of Economic Development. American Economic Journal: Macroeconomics, 1-28.

Jorgenson, D. (2018). Production and welfare: progress in economic measurement. Journal of Economic Literature, 867-919.

Jorgenson, D., \& Stiroh, K. (2000). US Economic Growth at the Industry Level. American Economic Review, 161-167.

Jorgenson, D., Mun, H., \& Kevin, S. (2005). Information Technology and the American Growth Resurgence. Cambridge, MA: MIT Press.

Jorgeson, D. W., \& Griliches, Z. (1967). The Explanation of Productivity Change. Review of Economic Studies, pp. 34:249-283.

Jorgeson, D. W., Gollop, F. M., \& Fraumeni, B. M. (1987). Productivity and US Economic Growth. Cambridge, MA: Harvard University Press.

Leontief, W. W. (1936). Quantitative Input and Output Relations in the Economic System of the United States. Review of Economics and Statistics, 105-25.

Nassif, A., Lucilene, M., Araújo, E. \& Feijó, C. 2020. Structural change and productivity growth in Brazil: where do we stand? Brazil. J. Polit. Econ. 40(2).

Nogueira, M., Infante, R., \& Mussi, C. (2014). Produtividade do Trabalho e Heterogeneidade Estrutural no Brasil Contemporâneo. Em C. R. De Negri F, Produtividade no Brasil: desempenho e determinantes, vol 1, 15-52. Brasília: IPEA:ABDI.

Oliner, S. D., \& Sichel, D. E. (2000). The Resurgence of Growth in the Late 1990s: Is Information Technology the Story? Journal of Economic Perspectives, 3-22.

Oulton, N. (2001). Must the Growth Rate Decline? Baumol's Unbalanced Growth Revisited. Oxford Economic Papers, 53(4), 605-627.

Oulton, N., \& O’Mahony, M. (1994). Productivity and Growth: A Study of British Industry 1954-1986. Cambridge: Cambridge University Press. 
Sasaki, H. (2007). The Rise of Service Employment and its Impact on Aggregate Productivity Growth. Structural Change and Economic Dynamics, 18(4), 438-459.

Sasaki, H. (2020). Is growth declining in the service economy? Structural Change and Economic Dynamics, 26-38.

Szirmai A. (2012), Industrialization as an Engine of Growth in Developing Countries, 1950-2005. Structural Change and Economic Dynamics, 23, pp. 406-420.

Szirmai A., Naudé W. and Alcorta L. (2013), Pathways to Industrialisation in the TwentyFirst Century: New Challenges and Emerging Paradigms, New York: United Nations University World Institute for Development Economics Research (UNU-WIDER).

Solow, R. (1956). A Contribution to the Theory of Economic Growth. Quarterly Journal of Economics, 70, 65-94.

Solow, R. (1957). Technical change and the aggregate production function. Review of Economics and Statistics, 39 (3): 312-320.

Ten Raa, T., \& Shestalova, V. (2011). The Solow residual, Domar aggregation, and inefficiency: a synthesis of TFP measures. Journal of Productivity Analysis, 71-77.

Timmer, M. P., \& van Ark, B. (2005). Does Information and Communication Technology Drive EU-US Productivity Growth Differentials? Oxford Economic Papers, 693-716.

Timmer, M., Dietzenbacher, E., Los, B., Stehrer, R., \& de Vries, G. (2015). An Illustrated User Guide to the World Input-Output Database: the Case of Global Automotive Production. pp. 575-605.

Tregenna F. (2009). Characterising Deindustrialisation: An Analysis of Changes in Manufacturing Employment and Output Internationally. Cambridge Journal of Economics, 33, pp. 433-466.

Trigg, A. (2020). Thirlwall's Law and uneven development under Global Value Chains: a multi-country input-output approach. Economic Structures 9, 4.

Diwert, W. E. (1976). Exact and Superlative Index Numbers. Journal of Econometrics, 115-145.

Wollf, E. (2013). Productivity Convergence: Theory and Evidence (Cambridge Surveys of Economic Literature). Cambridge: Cambridge University Press. 


\section{Declarations}

\section{- Availability of data and material}

We use the Socio-Economic Accounts (SEA) data from the World Input-Output Database (WIOD). The data comprises the period between 2000 and 2014, and 48 sectors for the Brazilian economy. Aiming to improve the visualisation results, we have split the sectors, besides the original 48 levels of aggregation from the data, to 10 and 3 levels of aggregation as can be seen in detail in the appendix. The original subdivision of sectors is given by the ISIC (International Standard Industrial Classification of All Economic Activities) revision n. 4, from the United Nations Statistics Division, which can be found at https://unstats.un.org/unsd/classifications/Econ/ISIC\#isic1 .

\section{- Competing interests}

None of the authors have any competing interests in the manuscript.

\section{- Funding}

Ricardo Araujo wishes to thank financial support from CNPq and Capes/Proex/PrintUnB. Theo Santini whishes to thank Capes/Print-UnB.

\section{- Authors' contributions}

All authors contributed equally to all sections. The authors read and approved the final manuscript.

\section{- Acknowledgements}

We wish to thank useful comments from Andrew Trigg and the participants of the Seminar on Production and Structural Change, hosted by The Open University and held at Hamilton House in London. The usual disclaimer applies. 
- Authors' information (optional)

Theo Santini, Associate Researcher, Brazilian Institute of Applied Economics (IPEA).

Ricardo Azevedo Araujo, Associate Professor, Department of Economics, University of Brasilia, Campus Universitário Darcy Ribeiro, Brasília-DF, Zip code: 70910-900. E-mail: rsaaraujo@unb.br. 


\section{Figures}
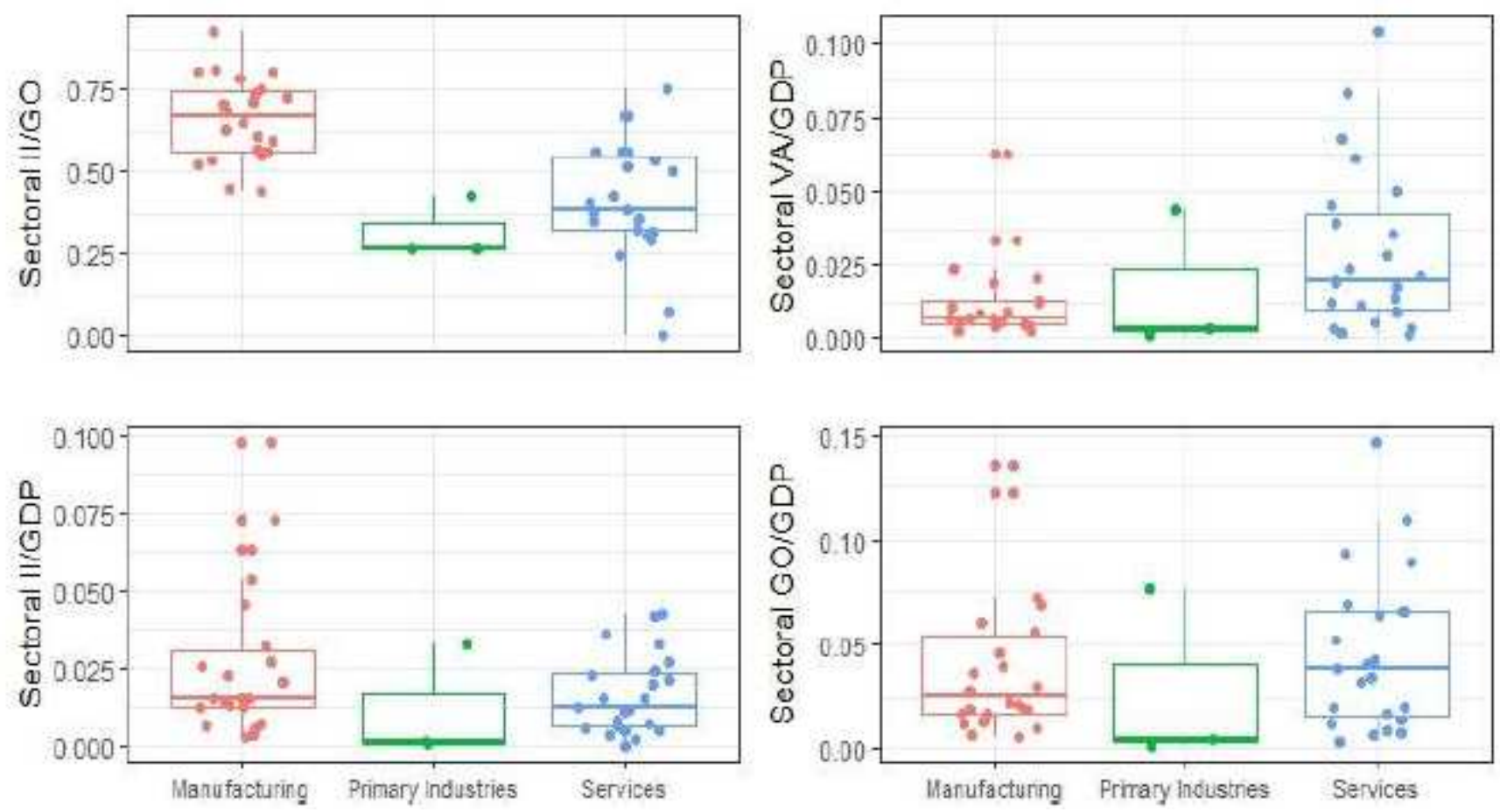

\section{Figure 1}

Characteristics and dispersion of Brazilian economy sectors Note: Sectoral dispersion for 48 and 3 levels of aggregation: on the top side there are, respectively, the share of sectoral intermediate inputs to gross output and the share of sectoral value added in the GDP. On the bottom side there are the share of sectoral intermediate input to GDP (sectoral density) and sectoral gross output to GDP (Domar Weight), in that order. Authors calculations using WIOD Brazilian data for 2010. 


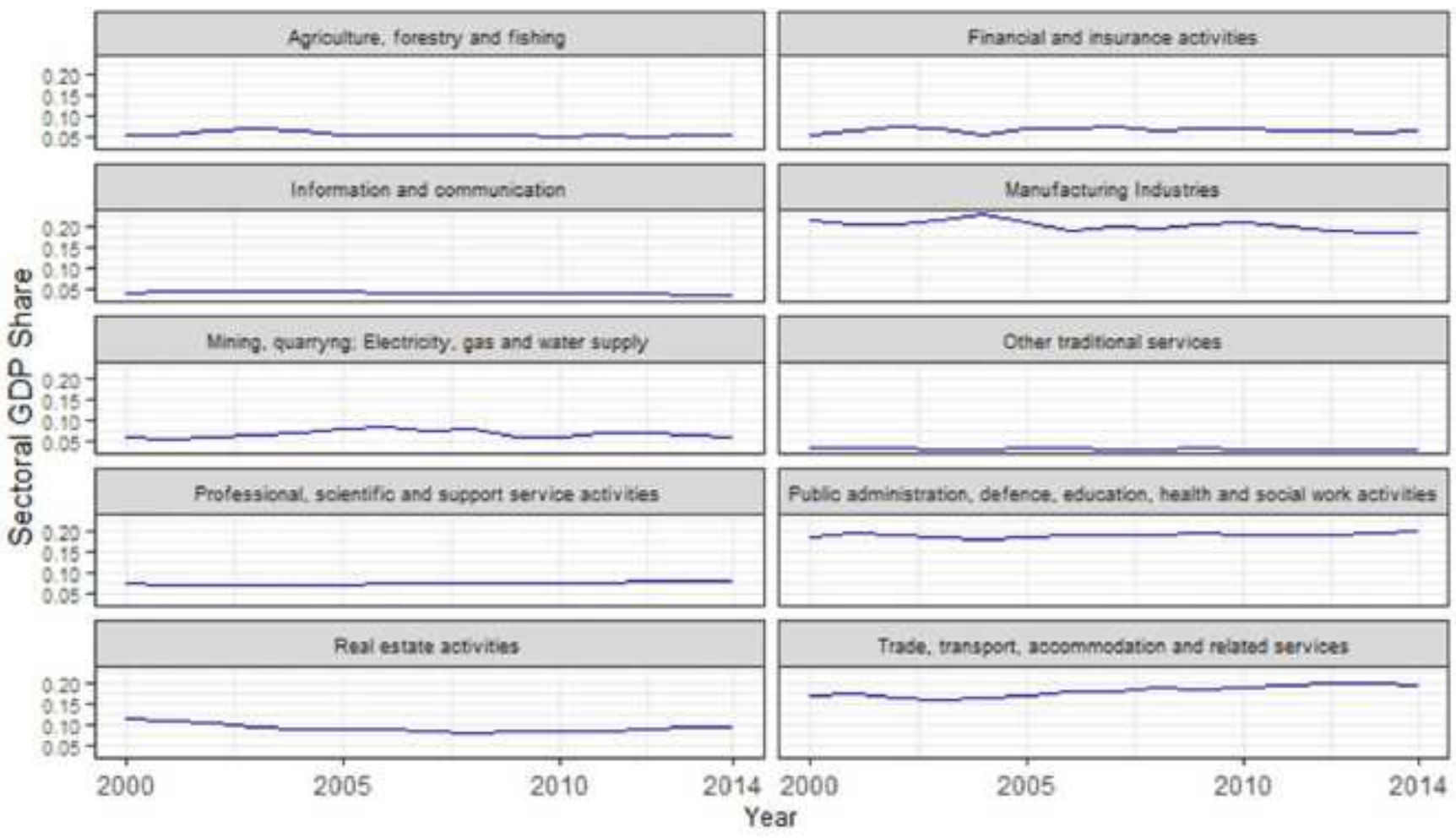

\section{Figure 2}

value-added share for 10 sectors in GDP Note: Authors calculations using WIOD Brazilian data

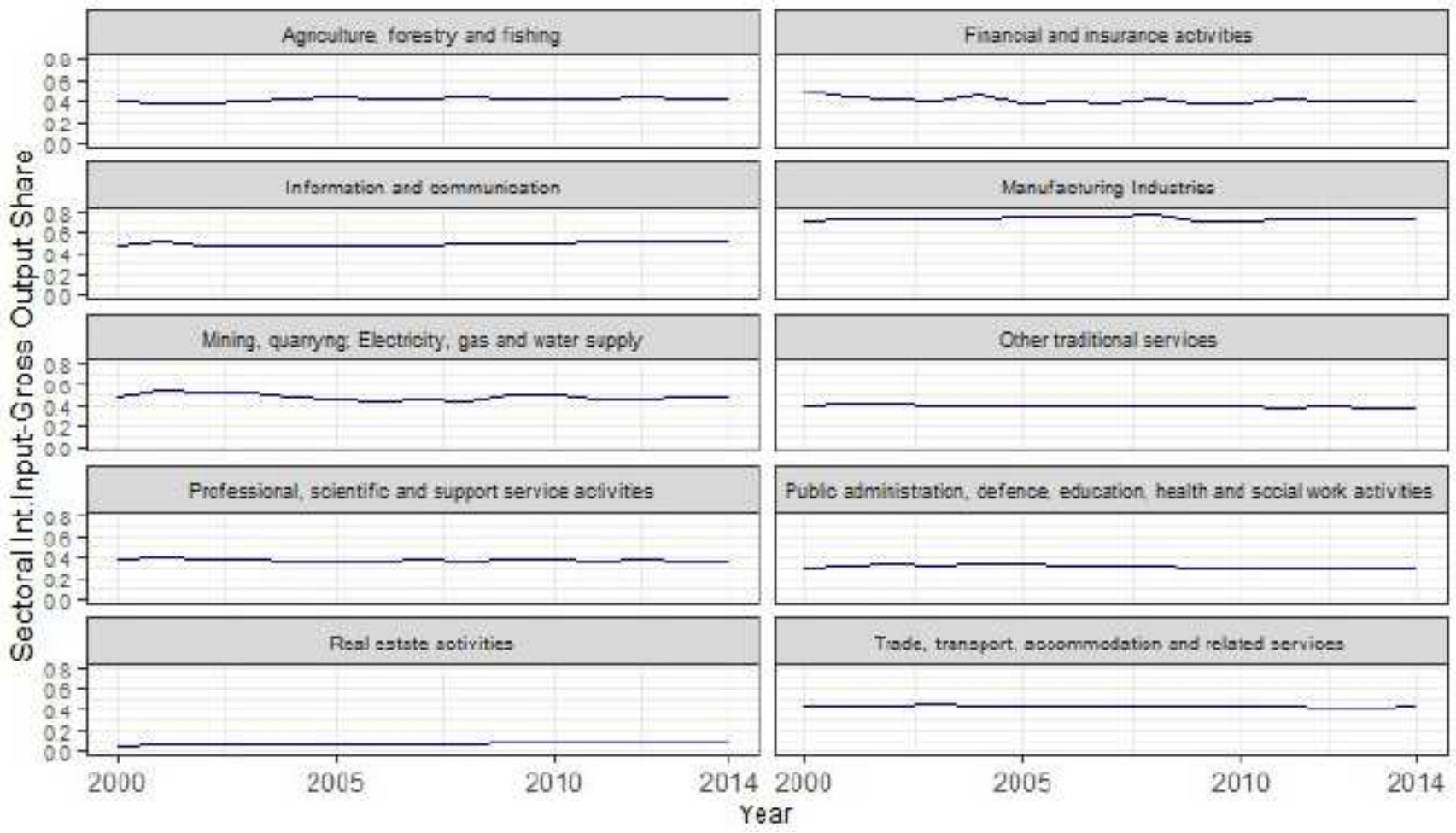

\section{Figure 3}


10 sectors intermediate input relative to gross output share Note: Authors calculations using WIOD Brazilian data

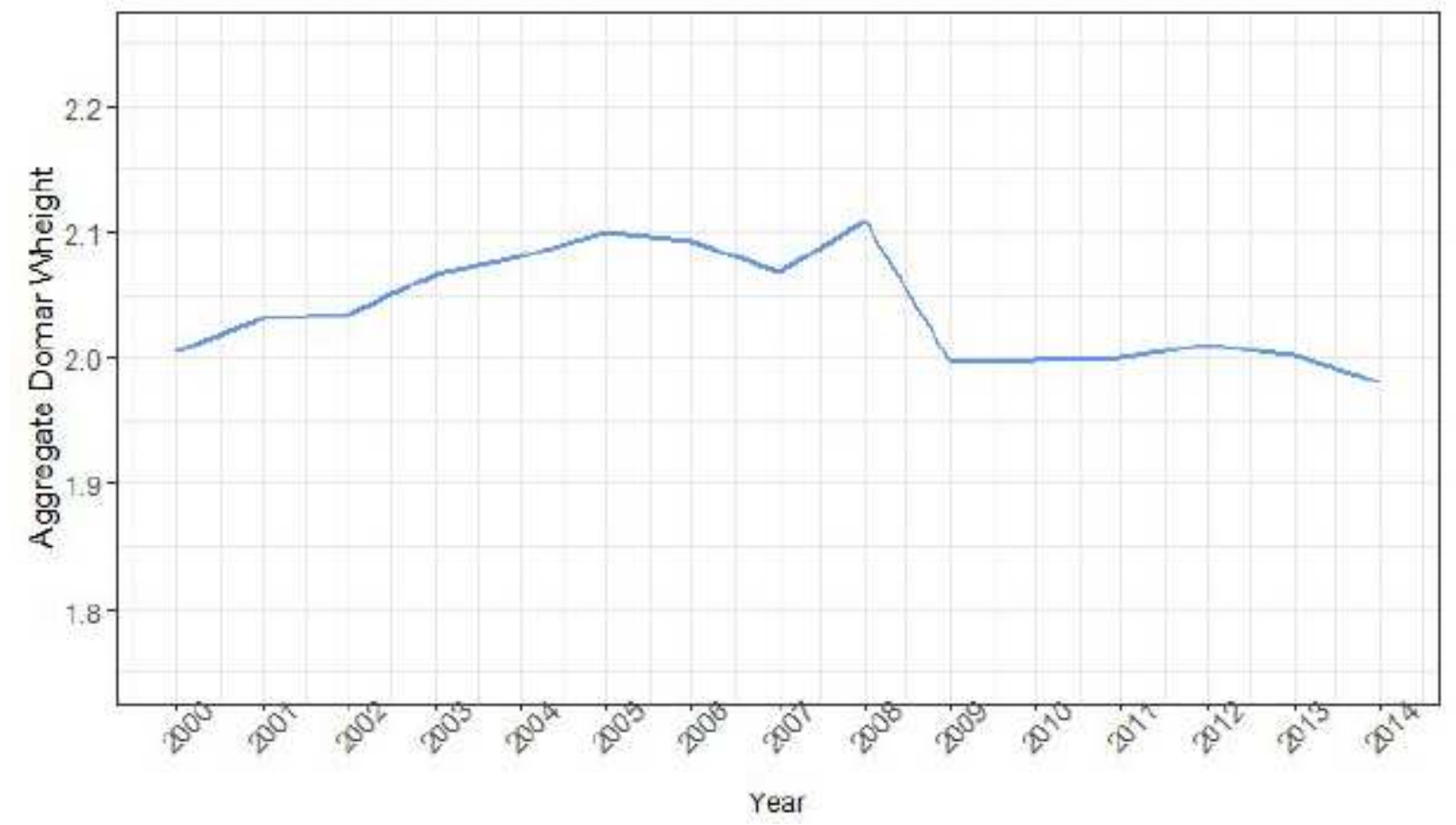

Figure 4

Sum of Brazilian Domar Wheights 2000 - 2014 Note: Author calculations using WIOD Brazilian data

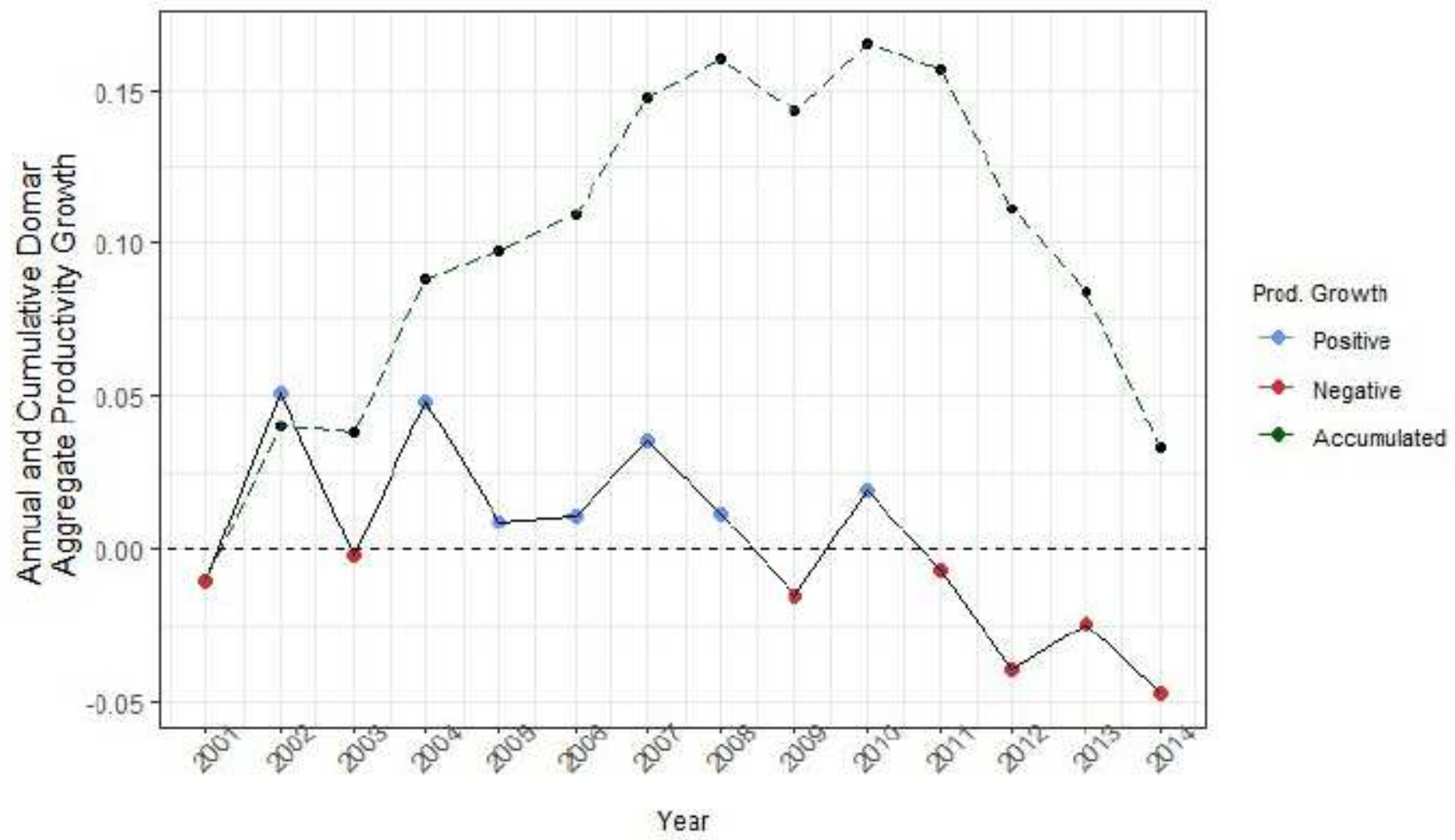

Figure 5 
Domar aggregation: yearly and cumulative productivity growth Note: Author calculations using WIOD Brazilian data

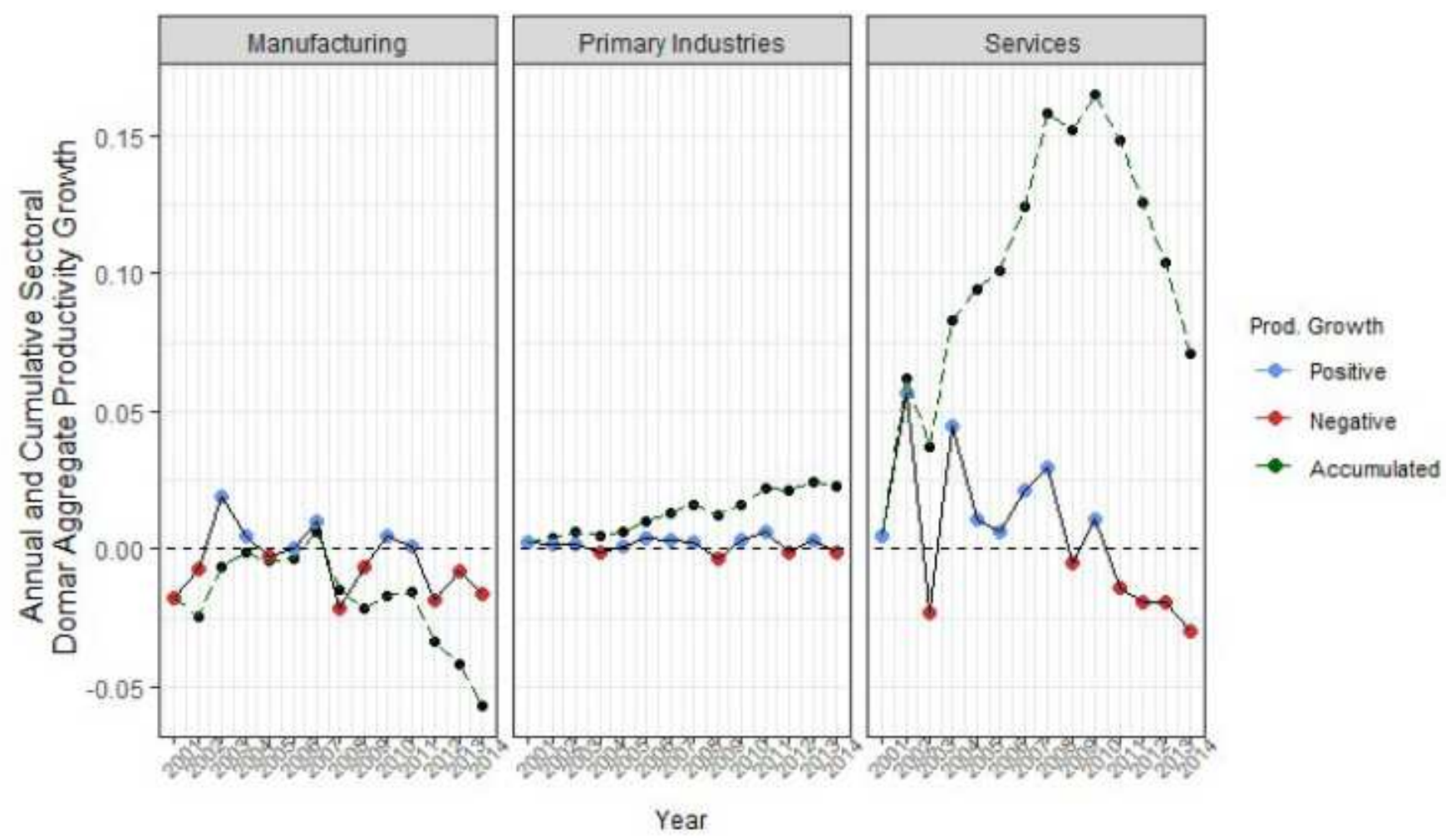

\section{Figure 6}

Domar aggregation: yearly and cumulative productivity growth decomposed by macrosectors Note: Author calculations using WIOD Brazilian data

\section{Supplementary Files}

This is a list of supplementary files associated with this preprint. Click to download.

- TablesJES.pdf 